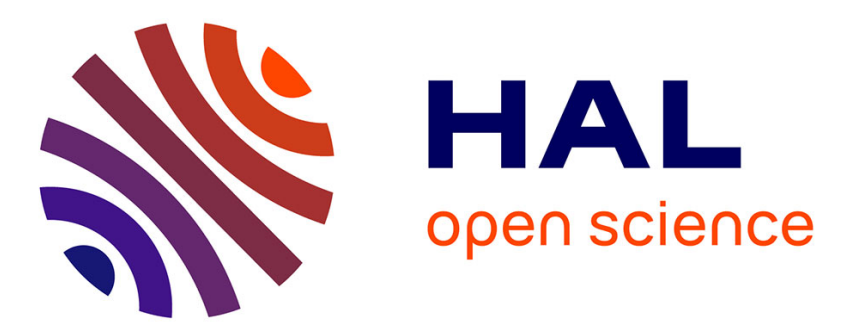

\title{
Effect of viscoplasticity on microfluidic cavity filling efficiency of a thermoplastic polymer in hot-embossing process
}

Gang Cheng, Thierry Barrière

\section{- To cite this version:}

Gang Cheng, Thierry Barrière. Effect of viscoplasticity on microfluidic cavity filling efficiency of a thermoplastic polymer in hot-embossing process. International Journal of Advanced Manufacturing Technology, 2019, 103 (1-4), pp.549-565. 10.1007/s00170-019-03447-1 . hal-02867747

\section{HAL Id: hal-02867747 https://hal.science/hal-02867747}

Submitted on 20 Oct 2020

HAL is a multi-disciplinary open access archive for the deposit and dissemination of scientific research documents, whether they are published or not. The documents may come from teaching and research institutions in France or abroad, or from public or private research centers.
L'archive ouverte pluridisciplinaire HAL, est destinée au dépôt et à la diffusion de documents scientifiques de niveau recherche, publiés ou non, émanant des établissements d'enseignement et de recherche français ou étrangers, des laboratoires publics ou privés.

\section{(c)(1)}

Distributed under a Creative Commons Attribution| 4.0 International License 


\title{
Effect of viscoplasticity on microfluidic cavity filling efficiency of a thermoplastic polymer in hot-embossing process
}

\author{
Gang Cheng ${ }^{1} \cdot$ Thierry Barriere ${ }^{2}$
}

\begin{abstract}
The micro hot-embossing process is an efficient and low-cost manufacturing process that can produce components with complex geometries in a wide variety of materials. The physical behaviour of the material needs to be investigated to achieve optimisation of the process. Many experimental results have been presented in the literature; however, modelling of the material properties and simulations of the process to improve the microreplication quality are still lacking. The principal scientific challenge in the numerical simulation is to provide an efficient material behaviour law to describe the deformation of the material during the process. The physical constitutive behaviour law of polymer plates in the hot-embossing process can be treated as viscoelastic or viscoplastic, depending on the various process boundary conditions. This study mainly concerns the identification of a physical constitutive behaviour law for an amorphous polymer poly (methyl methacrylate) (PMMA), which is used in hot-embossing processes at the microscale. Uniaxial compression tests were carried out under various temperature conditions slightly above the glass transition temperature $\left(T_{g}\right)$ of the polymer, and the viscoplastic behaviour of the polymer was characterised. In the present study, the fabrication of a complex microfluidic device is treated as a case study, focusing on the filling stage of the process. Modelling in numerical software using the implemented polymer behaviour model was realised, and the influence of different processing and material parameters on the filling efficiency was investigated at the microscale in two different zones (channel and reservoir). Specific related microreplications in the processing temperature range from $T_{g}+20{ }^{\circ} \mathrm{C}$ to $T_{g}+40{ }^{\circ} \mathrm{C}$ with different material parameters were also studied and compared. The results of the simulation were in good agreement with the experimental results in terms of replication for the PMMA amorphous thermoplastic polymer compared at different microscales and in different zones, confirming the efficiency of the proposed approach with different comparisons in 2D and 3D cases. Moreover, the models can be used when similar behaviours are observed in amorphous thermoplastics and extended to other micro hot-embossing components.
\end{abstract}

Keywords Micro hot-embossing - Amorphous thermoplastic polymer - Replication at microscale - Viscoplastic behaviour . Simulation

\section{Introduction}

Micro hot-embossing is widely used because it is one of the most efficient processes for the manufacture of polymeric components [28]. It provides several advantages compared

Gang Cheng

gang.cheng@insa-cvl.fr

1 Gabriel Lamé Mechanics Laboratory, INSA Centre Val de Loire, 3 Rue de la Chocolaterie, 41034 Blois, France

2 Univ. Bourgogne Franche-Comté, FEMTO-ST Institute, UFC/ CNRS/ENSMM/UTBM, Department of Applied Mechanics, F-25000 Besançon, France to other polymer forming processes, such as a relatively low cost of moulding tools, flexibility in the embossing material, lower processing temperature, and simple operation [22]. These advantages enable the wide use of hot-embossing for the fabrication of microcomponents in various applications. Andersen et al. [2] proposed a fast, low-temperature, lowpressure method to fabricate polymer-based microneedles for drug delivery. Hot-embossing can also be used for microscale replication with various embossed materials. Kurita et al. [18] proposed a laser-assisted hot-embossing process with glass material. Their results demonstrated that the die mould could be heated with a laser to improve the embossing efficiency in the replication of microstructures. The replication efficiency depends on the performance of the moulding tool, which should be strong, durable, and capable of manufacturing 
features with a particular size and aspect ratio [32]. Most of the final components are manufactured on a planar surface in this process, and high-quality replication of microstructures has been obtained with a high aspect ratio [4].

Polymers are important materials in microreplication owing to their low cost and wide range of physical properties. Polymers have played a significant role in the development of multi-functional materials. A general review of the printing technologies for smart materials based on polymers was provided by Oliveira et al. [23] and discussed the excellent integration and wide application of polymer-based materials in the electrical and mechanical engineering fields. Lee et al. [19] demonstrated that thermoplastic polymers are suitable for the fabrication of modular-assembly microfluidic devices via the hot-embossing process. The embossed material is heated to a certain temperature that allows the material to flow into the cavities of the mould insert. For thermoplastic polymers, the processing temperature is slightly above their glass transition temperature $\left(T_{g}\right)$, and drastic changes in physical properties such as the activation energy, specific heat, and coefficient of thermal expansion of the polymer occur in this temperature range. The rheology, creep rate, and various mechanical properties, such as the toughness and strength, also exhibit major changes at the $T_{g}$ [16]. The physical behaviour of polymers, including physical properties such as the viscoelasticity and viscoplasticity, are highly dependent on the loading time and temperature. An increasing number of microcomponents have been fabricated with thermoplastic polymers via the micro hot-embossing process in recent years; however, the lack of numerical models and simulations restricts the further development of the process [27].

Much research on the viscoelastic and viscoplastic behaviours of polymers has been published. The term 'elastic' signifies recoverable strain after deformation [21]. The term 'plastic' indicates unrecoverable strain, which is considered to be relevant to the magnitude of the local stress or strain. The term 'visco' indicates strain that changes with time [17]. A three-dimensional constitutive model was presented by Bardenhagen et al. [3]. This model could be used to describe the viscoplastic deformation of polymeric materials under isothermal conditions. The viscoplastic behaviour of polymers has been characterised qualitatively using stress relaxation and creep tests. A constitutive model that combines nonlinear viscoelastic effects and plasticity was proposed by Frank and Brockman [11]. The time-dependent and nonlinear responses of thermoplastic polymers in the glassy regime were taken into account in this model. The model seems to be suitable for describing the effects of hydrostatic pressure and strain on the behaviour of thermoplastics. Another constitutive model for describing the viscoplastic behaviour of amorphous polymers was proposed by Drozdov [7]. The heterogeneity of amorphous polymers at the microscale is described by this model, and fair agreement has been obtained between the experimental and numerical results for uniaxial relaxation tests. Constitutive equations for the viscoplastic damage behaviour of rubber particle-loaded thermoplastic polymers were investigated by Zairi et al. [31]. The effects of the strain rate, strain magnitude, and damage fraction evolution were described in the model. The model has been validated with experimental data and provides a correct prediction of the nonlinear deformation of loaded polymers associated with the influence of void growth. A novel test to separate the relative stress contributions of semi-crystalline polymers was presented by Holmes and Loughran [13]. The aim of their work was to facilitate the constitutive modelling of polymer behaviour along with the elastic, viscoelastic, and viscoplastic material properties. A viscoplastic model for glassy polymers was developed to analyse their inelastic deformation using a generalised viscodamage and viscohealing theory by Voyiadjis et al. [25]. The proposed viscoplastic model is considered an efficient numerical tool to evaluate ductile damage in polymers. It can be used to predict large inelastic deformation under low cycle fatigue conditions. Yu et al. [30] proposed a cyclic constitutive model to describe the nonlinear viscoelastic and viscoplastic behaviour of polymers. The thermodynamic material behaviour was deduced using the dissipative inequality and constructed Gibbs free energy. A largedeformation viscoelastic and viscoplastic model was proposed by Gudimetla and Doghri [12] to describe the strongly nonlinear finite strain response of a thermoset polymer. Good agreement between the simulation and experimental results for the compression-dominated deformation mode has been achieved, which demonstrates the excellent prediction ability of the proposed viscoelastic and viscoplastic model. A 3D fractional viscoplastic model to describe the deformation of amorphous polymers was presented by Xiao et al. [29]. The performance of the proposed model was confirmed using the stress response under uniaxial deformation at various strain rates and temperatures. The polymer recovery behaviour during the hot-embossing process was studied by Wang et al. [26]. They showed that the recovery of the polymer reduces the filling efficiency during the unloading step of the process, but this occurs only when the strain energy is high enough to break the interfacial bonding between the die cavity and the polymer substrate. The time-temperature superposition principle was applied to study the large-deformation mechanical behaviour of poly (methyl methacrylate) (PMMA) by Federico et al. [10]. A so-called equivalent strain rate, which describes the relationship between the strain rate and the temperature, was considered as a unique parameter to characterise the polymer complex properties above the $T_{g}$. Tensile test results were used to validate the modelling efficiency not only in the rubbery region near and slightly above the $T_{g}$ but also in the viscous region. The viscoelastic and viscoplastic behaviours of the polymer were taken into account in the modelling of fatigue damage by Holopainen and Barriere [14]. 
Numerical modelling of the fatigue damage development was accomplished by shifting an endurance surface in an effective damage free stress space. This modelling approach was implemented using finite element software, and numerical tensile fatigue simulations were conducted for a polycarbonate specimen. The proposed model was shown to be suitable for predicting the isothermal fatigue behaviour of amorphous thermoplastic polymers.

The micro hot-embossing process has been widely used for manufacturing polymer-based components for microelectromechanical, biomedical, and optical devices. Many studies on the mould design, polymer processing, and optimisation have been conducted, but investigations of the physical behaviours of the material and efficient numerical modelling tools are still lacking. The material physical behaviour needs to be investigated clearly in order to satisfy the rapid development of the micro hot-embossing process. The principal scientific challenge in the numerical simulation is the development of an efficient material behaviour law to describe the material deformation during the process on a microscale. Polymer-based microfluidic devices using various materials have attracted much attention in the medical field owing to their short response time, high sensitivity, and low analyte consumption [20]. In this study, the elastic-viscoplastic behaviour of an amorphous polymer was characterised in the temperature range of the hot-embossing process. Polymer uniaxial compression tests with cylindrical specimens were also carried out. Different stress and strain loads were applied to the polymer to investigate the complex behaviour in the temperature range from $T_{g}+20^{\circ} \mathrm{C}$ to $T_{g}+40{ }^{\circ} \mathrm{C}$. The fabrication of amorphous polymer-based microfluidic devices by micro hotembossing was chosen as an example and was modelled in finite element software using the proposed model. Two different cavity areas in the microfluidic device were specifically studied at the microscale from $T_{g}+20^{\circ} \mathrm{C}$ to $T_{g}+40^{\circ} \mathrm{C}$ during the filling stage: the reservoir and the channel. Specific related studies with different filling efficiencies under the three formation temperature conditions and varying material parameters are also discussed in this paper. Furthermore, the simulation results were compared with those of PMMA experiments with hot-embossed structured components described in previous studies to validate the proposed model implemented in the finite element software and to verify the efficacy of this approach with different comparisons in $2 \mathrm{D}$ and $3 \mathrm{D}$ cases. A summary of the nomenclature including all of the symbols used in this paper is provided in Table 1.

\section{Polymer elastic-viscoplastic behaviour model}

An elastic-viscoplastic behaviour law was proposed to describe the mechanical properties of the amorphous
Table 1 Nomenclature used in this paper

\begin{tabular}{ll}
\hline$T_{g}$ & Glass transition temperature \\
$\varepsilon_{t}$ & Total compression strain \\
$\varepsilon_{e l}$ & Elastic strain \\
$\varepsilon_{p l}$ & Plastic strain \\
$\sigma_{t}$ & Total compression stress \\
$E$ & Elastic modulus \\
$\sigma_{r}$ & Relaxation stress \\
$a$ & Constant to describe the relaxation stress \\
$b$ & Constant to describe the relaxation stress \\
$t$ & Relaxation time \\
$g$ & Equilibrium stress \\
$H_{o}$ & Initial height of the specimen in compression test \\
$H$ & Final height of the specimen in compression test \\
$D_{o}$ & Initial diameter of the specimen in compression test \\
$D$ & Final diameter of the specimen in compression test \\
$\varepsilon_{c}$ & Compression true strain \\
$\sigma_{c}$ & Compression true stress \\
$F_{c}$ & Compression force \\
$S$ & Final cross-sectional areas of specimen \\
$S_{0}$ & Initial cross-sectional areas of specimen \\
$\varepsilon_{c}$ & Compression true strain rate \\
$v$ & Drop rate of the upper platen in compression test \\
$R^{2}$ & Coefficients of determination \\
$d 1$ & Length of the small interspace in the axisymmetric model \\
$h 1$ & Height of the small interspace in the axisymmetric model \\
$d 2$ & Length of the small interspace in the 2D plane strain model \\
$h 2$ & Height of the small interspace in the 2D plane strain model \\
\hline &
\end{tabular}

thermoplastic polymer in the hot-embossing temperature range, which was slightly above its $T_{g}$. These behaviour laws were implemented in numerical software based on the finite element method to perform the numerical simulation of the hot-embossing process.

In this study, the numerical simulation of the hotembossing process is separated into two steps: the first is the filling stage, in which the PMMA substrate is compressed by the mould microfluidic die insert, and the second is the packing stage, in which the PMMA flow continues to fill the microcavities after the filling stage. The filling stage occurs in a very short time (normally less than $1 \mathrm{~s}$ ), and the elastic-plastic behaviour of the polymer dominates the deformation of the polymer flow. Therefore, the packing stage lasts for a relatively long time, and the polymer viscous behaviour dominates the deformation of the polymer flow. Nearly $90 \%$ of the deformation of the polymer substrate occurs during the filling stage in the hotembossing process. Two different behaviour laws have been proposed in this study: one is an elastic-plastic model used in the filling stage and the other is a viscoelastic model used in the packing stage. 
A classic elastic-plastic function was proposed to describe the polymer deformation in the filling stage. The total compression strain of the polymer was divided into the elastic strain and the plastic strain as follows:

$\varepsilon_{t}=\varepsilon_{\mathrm{el}}+\varepsilon_{\mathrm{pl}}$

The elastic strain, $\varepsilon_{\mathbf{e l}}$, is expressed by Hooke's law as follows:

$\varepsilon_{\mathrm{el}}=\sigma_{t} / E$

where $E$ is the elastic modulus, which is obtained from the uniaxial compression tests. The plastic strain, $\varepsilon_{p l}$, is characterised using the true stress-strain curves obtained in the uniaxial compression tests.

An exponential function is proposed to describe the viscoelastic behaviour of the polymer in the packing stage. The relaxation stress can be expressed with the following equation:

$\sigma_{r}=\operatorname{aexp}(-\mathrm{bt})+g$

where $\sigma_{\mathrm{r}}$ is the relaxation stress, $\mathrm{a}$ and $\mathrm{b}$ are the constants, and $\mathrm{g}$ is the equilibrium stress.

\section{Material characterisation}

\subsection{Uniaxial compression tests}

A Bose ${ }^{\circledR}$ ElectroForce ${ }^{\circledR}$ instrument was used to perform the polymer uniaxial compression tests according to the ASTM D4762 test method for the compressive properties of polymers. The cylindrical specimens were $18 \mathrm{~mm}$ length with a diameter of $10 \mathrm{~mm}$. The tested specimens were annealed at the testing temperature for $1 \mathrm{~h}$ to homogenise the specimen temperature before every mechanical test. The tested specimens were loaded in the centre of the space between two platens in a temperature oven, and the specimen temperature was controlled using a thermocouple. The lower platen was fixed, and a compression load cell was used to measure the force on the specimen. The strain rate or stress rate of the specimens was controlled using a WinTest ${ }^{\circledR}$ digital control system.

The mechanical testing of the compression specimen was performed at a temperature slightly above the $T_{g}$. The true stress-true strain curves for the amorphous PMMA were obtained at various load and strain rates. The polymer specimen deformation during the compression test is described in Fig. 1. Two assumptions were made in the determination of the PMMA true stress-strain curve: the polymer specimen volume remains constant during the mechanical testing, and the specimen shape remains cylindrical after the compression test. As

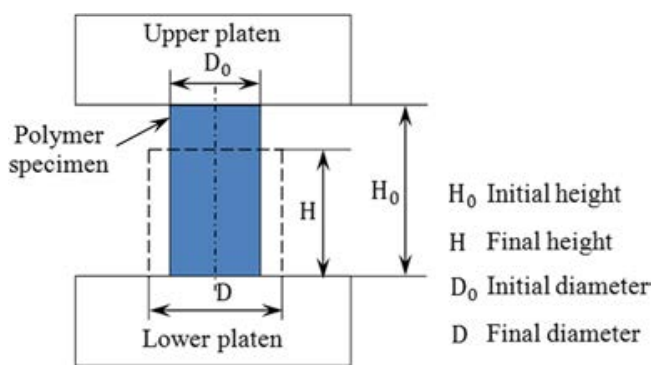

Fig. 1 Deformation of the cylindrical polymer specimen in the compression tests

shown in Fig. 1, $H_{0}$ and $H$ are the initial and final heights of the tested specimen, respectively; $D_{0}$ and $D$ are the initial and final diameters of the cylindrical specimen, respectively.

A large deformation was observed during the compression tests; therefore, the PMMA compression true strain, $\varepsilon_{\mathrm{c}}$, was determined using the conventional logarithmic strain expression [6]:

$\varepsilon_{c}=\ln \left(H_{0} / H\right)$

To ensure that the compression true strain has a positive value, the terms in parentheses were inverted (in a compression test, $\mathrm{H}_{0}>H$, whilst in a tensile test, $\mathrm{H}>\mathrm{H}_{0}$ ).

The volume conservation assumption was applied to determine the compression true stress, $\sigma_{\mathrm{c}}$ :

$\sigma_{c}=F_{c} / S=\left(F_{c} H\right) /\left(S_{0} H_{0}\right)$

where $F_{c}$ is the compression force applied by the platens and $S_{0}$ and $S$ are the initial and final cross-sectional areas of the specimen, respectively.

The compression true strain rate, $\dot{\varepsilon}_{c}$, is equivalent to the derivative of the true strain with respect to time, expressed as follows:

$\dot{\varepsilon}_{c}=\mathrm{d} \varepsilon_{c} / \mathrm{dt}=\mathrm{v} /\left(H_{0}-\mathrm{vt}\right)$

where $t$ is the testing time and $\mathrm{v}$ is the drop rate of the upper platen corresponding to the displacement rate of the tested PMMA specimen; vt is the total downward displacement of the upper platen, corresponding to the total displacement of the polymer specimen.

\subsection{Identification of the elastic modulus for compression}

The elastic modulus of the amorphous PMMA specimen was determined at three different temperatures in the uniaxial compression tests: $T_{g}+20{ }^{\circ} \mathrm{C}, T_{g}+30{ }^{\circ} \mathrm{C}$, and $T_{g}+40^{\circ} \mathrm{C}$. A constant strain rate $\left(0.01 \mathrm{~s}^{-1}\right)$ was applied to the cylindrical 


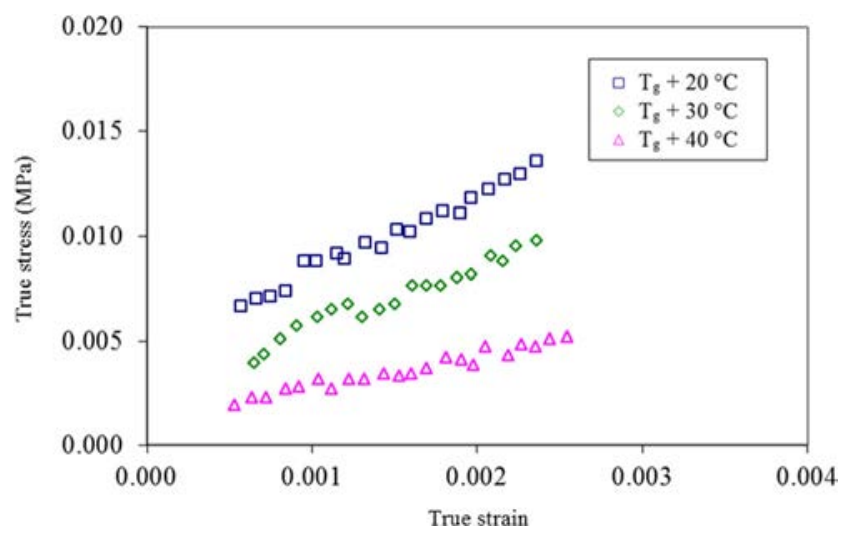

Fig. 2 True stress-true strain curves for PMMA with small deformation at temperatures slightly above $T_{g}$

specimen in the true strain range of 0.0005 to 0.0025 , where the PMMA specimen undergoes elastic deformation. The true stress-strain curves for the PMMA specimen at three different temperatures are shown in Fig. 2.

Based on the PMMA true stress-strain curves obtained at three different temperatures, the elastic modulus was determined with a linear regression analysis. A fitted linear regression model was proposed to identify the relationship between the true stress and strain. The PMMA elastic modulus was then obtained based on the fitting parameters of the regression model. Good agreement between the fitting model and experimental results was observed, with an $R$-squared (coefficient of determination) of 0.95 to 0.98 . PMMA elastic moduli of 3.61 MPa, $2.81 \mathrm{MPa}$, and $1.51 \mathrm{MPa}$ were obtained at $T_{g}+$ $20^{\circ} \mathrm{C}, T_{g}+30^{\circ} \mathrm{C}$, and $T_{g}+40{ }^{\circ} \mathrm{C}$, respectively. With increasing temperature, the PMMA elastic modulus decreased drastically: the elastic modulus decreased by $22 \%$ when the temperature increased by $10{ }^{\circ} \mathrm{C}$ from $T_{g}+20{ }^{\circ} \mathrm{C}$ to $T_{g}+30{ }^{\circ} \mathrm{C}$, whilst the elastic modulus decreased by $46 \%$ when the temperature increased by $10{ }^{\circ} \mathrm{C}$ from $T_{g}+30{ }^{\circ} \mathrm{C}$ to $T_{g}+40{ }^{\circ} \mathrm{C}$. The elastic modulus of the PMMA specimen at temperatures slightly above its $T_{g}$ is much lower than its elastic modulus at

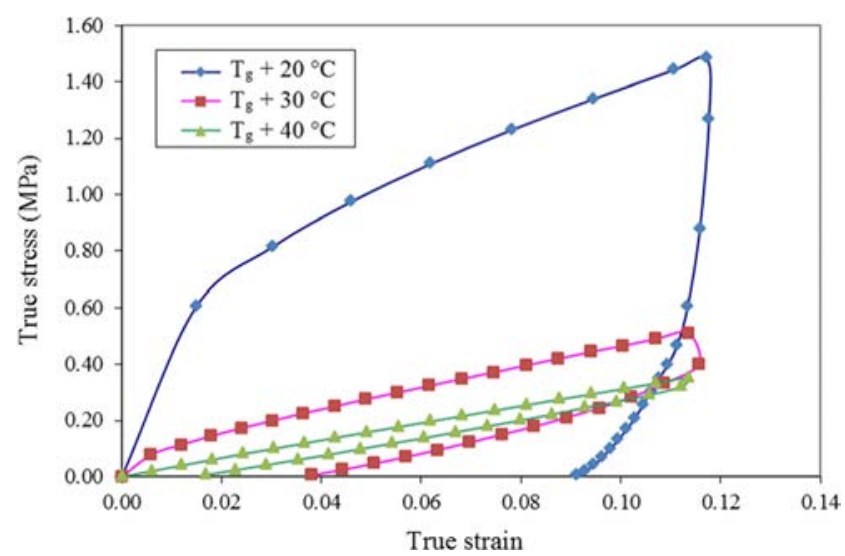

Fig. 3 True stress-true strain curves of PMMA with the same strain rate at temperatures slightly above the $T_{g}$
Table 2 Fitting parameters of the elastic-plastic model for the PMMA polymer at three temperatures

\begin{tabular}{|c|c|c|c|c|c|c|}
\hline \multirow[t]{2}{*}{ Polymer } & \multicolumn{2}{|l|}{$T_{g}+20^{\circ} \mathrm{C}$} & \multicolumn{2}{|c|}{$T_{g}+30^{\circ} \mathrm{C}$} & \multicolumn{2}{|l|}{$\mathrm{T}+40^{\circ} \mathrm{C}$} \\
\hline & $\sigma_{\mathrm{c}}(\mathrm{MPa})$ & $\varepsilon_{\mathrm{pl}}$ & $\sigma_{\mathrm{c}}(\mathrm{MPa})$ & $\varepsilon_{\mathrm{pl}}$ & $\sigma_{\mathrm{c}}(\mathrm{MPa})$ & $\varepsilon_{\mathrm{pl}}$ \\
\hline \multirow[t]{4}{*}{ PMMA } & 0.5 & 0 & 0.1 & 0 & 0.05 & 0 \\
\hline & 0.8 & 0.01 & 0.24 & 0.012 & 0.2 & 0.009 \\
\hline & 1.1 & 0.04 & 0.38 & 0.024 & 0.34 & 0.018 \\
\hline & 1.4 & 0.08 & 0.52 & 0.036 & & \\
\hline
\end{tabular}

room temperature of approximately $1300 \mathrm{MPa}$ [15]. The significant decrease in the elastic modulus of PMMA at high temperatures was confirmed in our analyses. A similar result was observed by Srivastava et al. [24].

\subsection{Identification of elastic-plastic behaviours as a function of temperature}

The uniaxial compression tests were conducted in a large strain range to determine the PMMA plastic behaviour. A constant strain rate of $0.03 \mathrm{~s}^{-1}$ was applied to the cylindrical specimen, which was then unloaded with the same true strain rate. A large deformation of the PMMA cylindrical specimen, which exceeded the true strain by $10 \%$, was observed during the compression tests. The PMMA true stress-strain curves with a constant strain rate at $T_{g}+20{ }^{\circ} \mathrm{C}, T_{g}+30{ }^{\circ} \mathrm{C}$, and $T_{g}+40^{\circ} \mathrm{C}$ are shown in Fig. 3 .

Based on the PMMA true stress-strain curves presented in Fig. 3, the initial stiffness of the polymer decreases dramatically with an increase in temperature. The true stress at a true strain of 0.11 is approximately $1.4 \mathrm{MPa}$ at $T_{g}+20^{\circ} \mathrm{C}$, but is no more than $0.3 \mathrm{MPa}$ at $T_{g}+40{ }^{\circ} \mathrm{C}$. The true stress-strain curve at $T_{g}+20^{\circ} \mathrm{C}$ shows that plastic deformation occurs even at a temperature above the $T_{g}$. However, the amount of permanentset decreases drastically with an increase in temperature from $T_{g}+20{ }^{\circ} \mathrm{C}$ to $T_{g}+40{ }^{\circ} \mathrm{C}$. At $T_{g}+20^{\circ} \mathrm{C}$, the true stress-strain curve exhibits a well-defined yield peak, which disappears at $T_{g}+30{ }^{\circ} \mathrm{C}$ and $T_{g}+40{ }^{\circ} \mathrm{C}$. The PMMA true stress-strain response is highly nonlinear in this temperature range. The plastic strain and stress of PMMA could be analysed at three temperature conditions. The compression stresses associated with the plastic strain at three temperatures are summarised in Table 2.

\subsection{Identification of viscoelastic behaviours as a function of strain level}

Stress relaxation tests were carried out to characterise the polymer viscoelastic behaviour in the temperature range slightly above its $T_{g}$. A constant true strain rate $\left(\dot{\varepsilon}_{c}=0.01\right.$ $\mathrm{s}^{-1}$ ) was applied to the polymer specimen until an ultimate 
Fig. 4 Relaxation stress of PMMA versus time for different strain levels at $T_{g}+20^{\circ} \mathrm{C}$

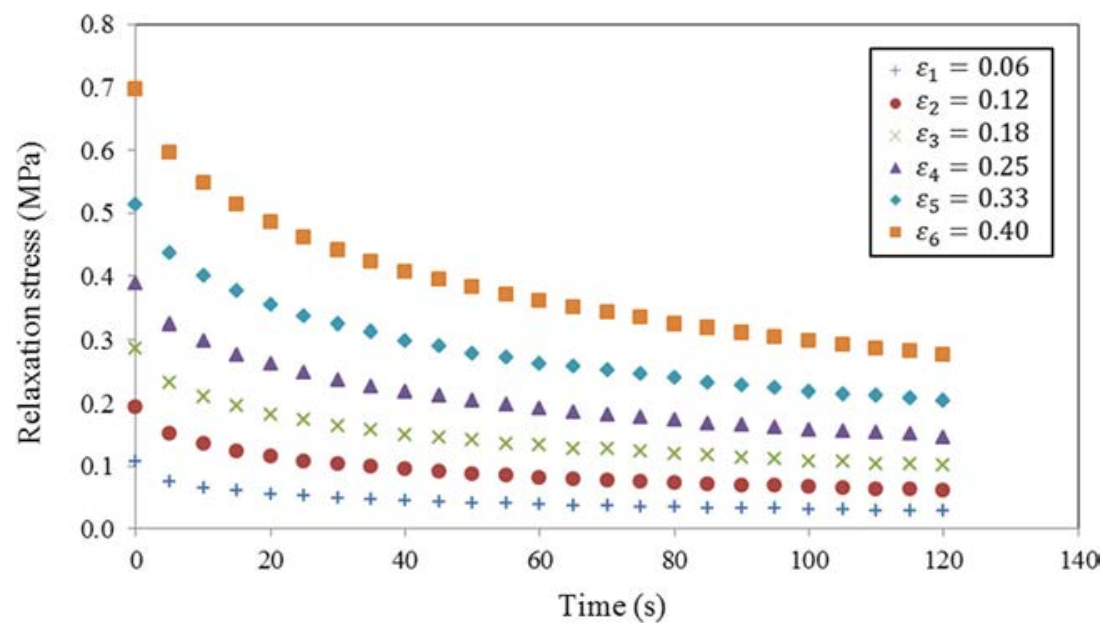

strain level was reached. Then, the variation in the true material stress versus time was recorded at a constant true strain. The polymer specimens were compressed at six different true strain levels and then released at $T_{g}+20{ }^{\circ} \mathrm{C}$. The relaxation stress of the polymer versus time obtained at different strain levels is illustrated in Fig. 4.

The relaxation stress curves in Fig. 4 show that the true stress of the PMMA specimen decreases with time. Initially, a large decrease in the true stress occurs (from 0 to $40 \mathrm{~s}$ ); then, the true stress becomes nearly constant until the end of the testing period (120 s). It is evident that the true stress increases with an increase in the compression true strain level. At $t=0 \mathrm{~s}$, the relaxation stress is approximately $0.70 \mathrm{MPa}$ for a true strain of 0.40 ; however, at the same time, the relaxation stress is approximately $0.10 \mathrm{MPa}$ for a true strain of 0.06 . A significant decrease in the polymer relaxation modulus is indicated by these curves. For example, at a strain of $\varepsilon_{6}=0.40$, the relaxation stress decreases by approximately $59 \%$ during the observation time.

Three parameters in the exponential equation need to be identified in order to describe the viscoelastic behaviour of the PMMA specimen at $T_{g}+20{ }^{\circ} \mathrm{C}$. The parameters in this model were determined using the relaxation stress curves shown in Fig. 4. The relaxation stress curves at six different strain levels were used to determine the identified parameters. The method

Table 3 Fitting parameters of the exponential equation for the PMMA polymer and associated coefficients of determination

\begin{tabular}{llllll}
\hline Polymer & Strain levels & $a$ & $b$ & $g(\mathrm{MPa})$ & $R^{2}$ \\
\hline PMMA & $\varepsilon_{1}=0.06$ & 0.0612 & 0.04308 & 0.03159 & 0.9815 \\
& $\varepsilon_{2}=0.12$ & 0.1116 & 0.03638 & 0.06508 & 0.9883 \\
& $\varepsilon_{3}=0.18$ & 0.1597 & 0.03229 & 0.1041 & 0.9907 \\
& $\varepsilon_{4}=0.25$ & 0.2149 & 0.02984 & 0.1498 & 0.9925 \\
& $\varepsilon_{5}=0.33$ & 0.2817 & 0.02797 & 0.204 & 0.9934 \\
& $\varepsilon_{6}=0.40$ & 0.3832 & 0.02756 & 0.2771 & 0.9934 \\
\hline
\end{tabular}

of least squares was used to determine the constants described in Eq. (3). The fitting parameters for the PMMA specimen and the associated coefficients of determination $\left(R^{2}\right)$ are listed in Table 3. The $R^{2}$ values for these six relaxation curves are approximately 0.98 or 0.99 , which indicates that the selected equation fits the stress relaxation curves for the tested PMMA specimens well.

\section{Numerical simulation of the filling stage of the micro hot-embossing process}

The numerical simulation of the micro hot-embossing process was performed using the finite element program Abaqus [1]. The proposed elastic-plastic and viscoelastic models, with the identified material parameters, were implemented in the software to describe the elastic-viscoplastic behaviour of the PMMA specimen at temperatures slightly above its $T_{g}$. The elastic-plastic model was used to describe the polymer deformation in the filling stage, while the viscoelastic model was used to describe the polymer deformation in the packing stage. In this section, some simulation results for the filling stage of the micro hot-embossing process are presented.

The boundary conditions of the numerical simulation were based on the experimental conditions for the fabrication of microfluidic devices by hot-embossing. The microfluidic devices were used for mixing or separating fluid flows. The dimensions of the steel mould die cavities are shown in Fig. 5. The microcavity structure was fabricated using laser ablation [5]. A PMMA substrate with a thickness of $2 \mathrm{~mm}$ was used to fabricate and replicate the microfluidic devices. In this process, the two-part mould, including the die insert and polymer substrate, is heated to slightly above the polymer $T_{g}$. Then, the moving mould plate moves forward to compress the polymer substrate, which has been placed between the moving and fixed mould die. The polymer flows into the mould die to fill the microcavities. The gap between the 


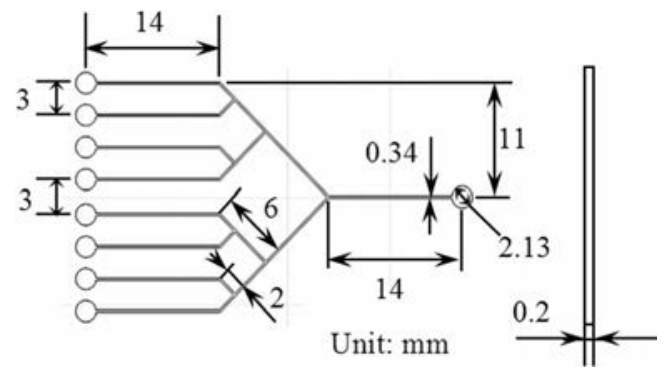

Fig. 5 Dimensions of microcavities in the microfluidic device

PMMA substrate and the microfluidic mould die is maintained under pressure at the compression temperature for a defined time period. At the end of the hot-embossing process, the mould plates and the replicated polymer substrate are cooled to a temperature below the $T_{g}$ and the embossing force is released.

The dimensions of the geometric models created in the numerical software were consistent with the actual dimensions of the microfluidic mould die insert shown in Fig. 5. The mould die insert was considered a rigid body, which exhibited no deformation during the hot-embossing process. The $3 \mathrm{D}$ geometric models of the polymer substrate and the mould die insert were created, but only the polymer viscoelastic behaviour was considered during the embossing process [5]. Although numerical simulation with the 3D microfluidic geometric model could show the global deformation of the polymer substrate during the micro hot-embossing process, it presented some difficulties in investigating the filling ratio of the microcavities.

Owing to the specific geometric features of the replications obtained by hot-embossing, different geometric models were created in the numerical software. Two different zones in the microfluidic device were selected to create the numerical model used in the simulations: the reservoir and the channel, as shown in Fig. 6. A 2D model comprising the mould microfluidic die cavity and PMMA substrate was designed. The micro hot-embossing process was performed under different temperature conditions to study the effect of the embossing temperature on the filling efficiency. A four-node bilinear quadrilateral mesh was used for the simulation, and the mesh size was adjusted based on the polymer deformation

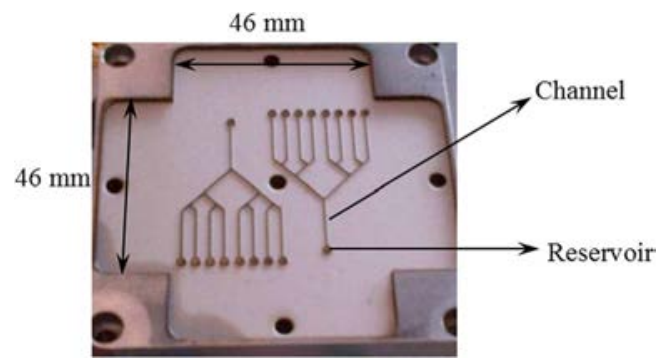

Fig. 6 Front view of the mould insert, showing the two zones selected for the numerical simulation: the reservoir and the channel during the filling step of the hot-embossing. The region exhibiting large deformation of the polymer substrate was meshed using a smaller element size to reduce the effect of the element size and improve the simulation accuracy. A total of 1482 elements were generated in the reservoir zone, and 4510 elements were generated in the channel zone.

\subsection{Filling of reservoir zone of microfluidic device}

For the reservoir zone, an axisymmetric model was created in the numerical software, with a diameter of $2.13 \mathrm{~mm}$ and height of $0.20 \mathrm{~mm}$. The friction between the PMMA substrate and the microfluidic mould die was not taken into account in this simulation. The PMMA substrate was first heated to $T_{g}+$ $20{ }^{\circ} \mathrm{C}$; then, it was heated to $T_{g}+30{ }^{\circ} \mathrm{C}$, and finally to $T_{g}+$ $40{ }^{\circ} \mathrm{C}$. The mould plate fell by approximately $0.20 \mathrm{~mm}$ to compress the PMMA substrate, and the PMMA flow filled the microcavities, as shown in Fig. 7.

The von Mises stress of the polymer decreases with the increase in temperature from $T_{g}+20{ }^{\circ} \mathrm{C}$ to $T_{g}+40{ }^{\circ} \mathrm{C}$, as shown in Fig. 8. Less compression force is required to compress the polymer substrate at the higher temperature of $T_{g}+$ $40{ }^{\circ} \mathrm{C}$. The most important value of the stress in the polymer substrate appears at the bottom of the reservoir, which exhibits maximum deformation of the polymer substrate. The polymer was pushed from left to right to fill the cavities in the mould die.

Another efficient way to compare the different processing temperatures is to investigate the effective strain distribution, as demonstrated by Esmaeilpour et al. [8,9]. The effective strain distributions of the polymer substrate under three processing temperature conditions $\left(T_{g}+20^{\circ} \mathrm{C}, T_{g}+30{ }^{\circ} \mathrm{C}\right.$, and $T_{g}+40{ }^{\circ} \mathrm{C}$ ) are presented in Fig. 9. For all of the temperature conditions, the highest the effective strains occur in the contour of the reservoirs because the polymer flow has been pushed up to fill the microcavities in the mould die. The next highest effective strains are located at the bottom of the polymer substrate under the contour of the reservoirs, which indicates that the polymer in this zone is not only compressed by the mould but is also pushed by the polymer flow to move to the right side. The highest effective strains occur at a temperature of $T_{g}+20^{\circ} \mathrm{C}$. This indicates that the polymer substrate exhibits more plastic behaviour at $T_{g}+20^{\circ} \mathrm{C}$, which is consistent with the investigation of the material characterisation.

The vertical displacements of the polymer substrate under processing temperature conditions of $T_{g}+20^{\circ} \mathrm{C}, T_{g}+30{ }^{\circ} \mathrm{C}$, and $T_{g}+40{ }^{\circ} \mathrm{C}$ are presented in Fig. 10 . The height of the embossed cavities in the polymer substrate are $0.1928 \mathrm{~mm}$, $0.1935 \mathrm{~mm}$, and $0.1929 \mathrm{~mm}$ for $T_{g}+20^{\circ} \mathrm{C}, T_{g}+30{ }^{\circ} \mathrm{C}$, and $T_{g}+40{ }^{\circ} \mathrm{C}$, respectively. The polymer at the bottom was compressed towards the right side to fill the cavities of the microfluidic device. The polymer at the top surface was raised and then compressed by the mould die. As a result, there is a 


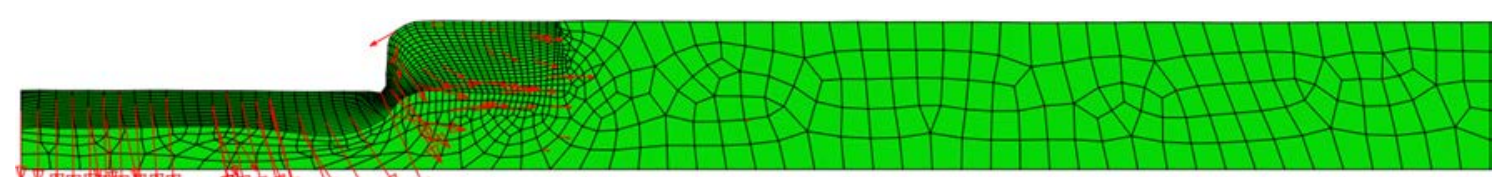

Fig. 7 Polymer flow direction in the axisymmetric model of the filling step

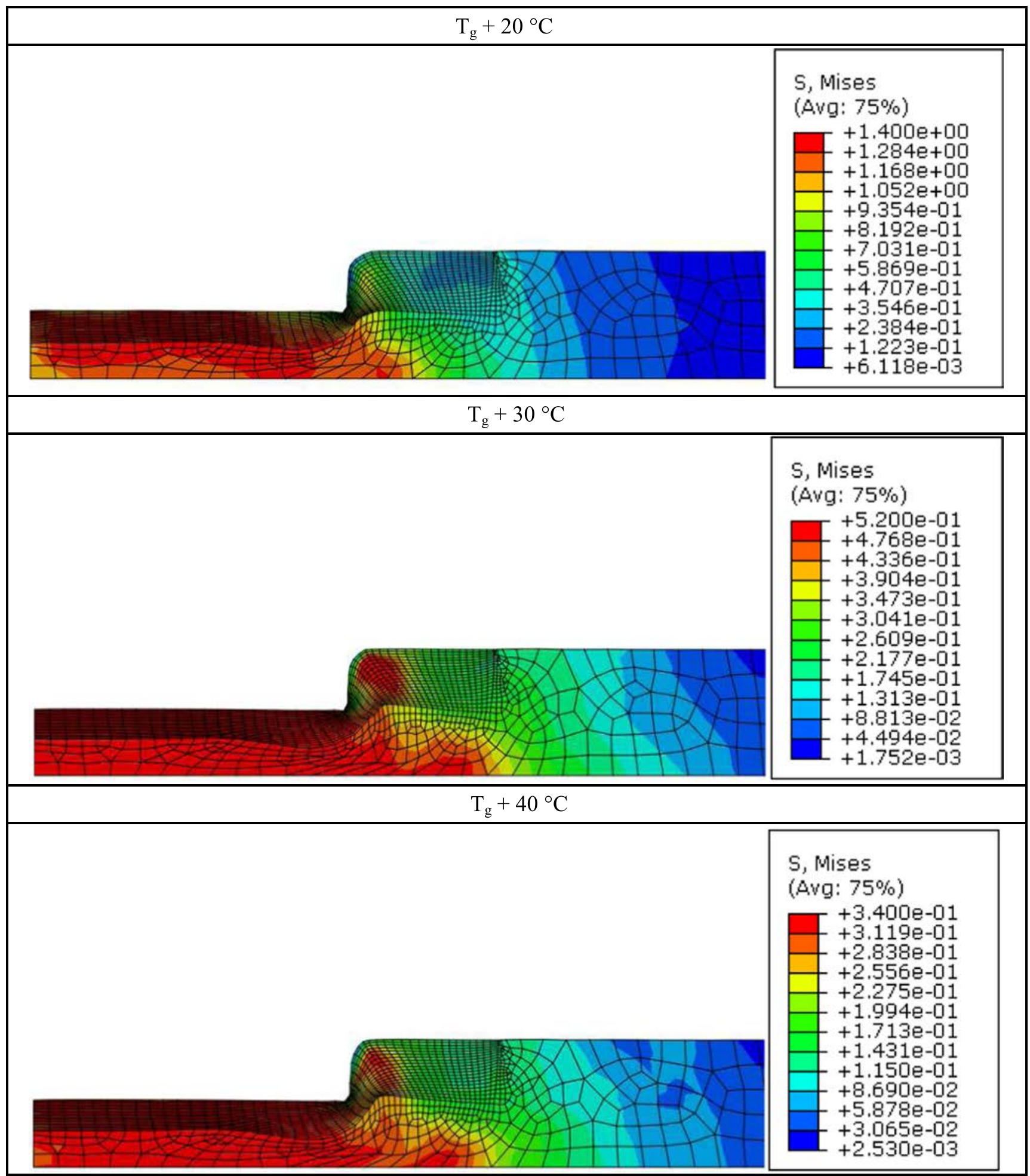

Fig. 8 Von Mises stresses of the polymer substrate in the axisymmetric model after the filling stage under different temperature conditions 


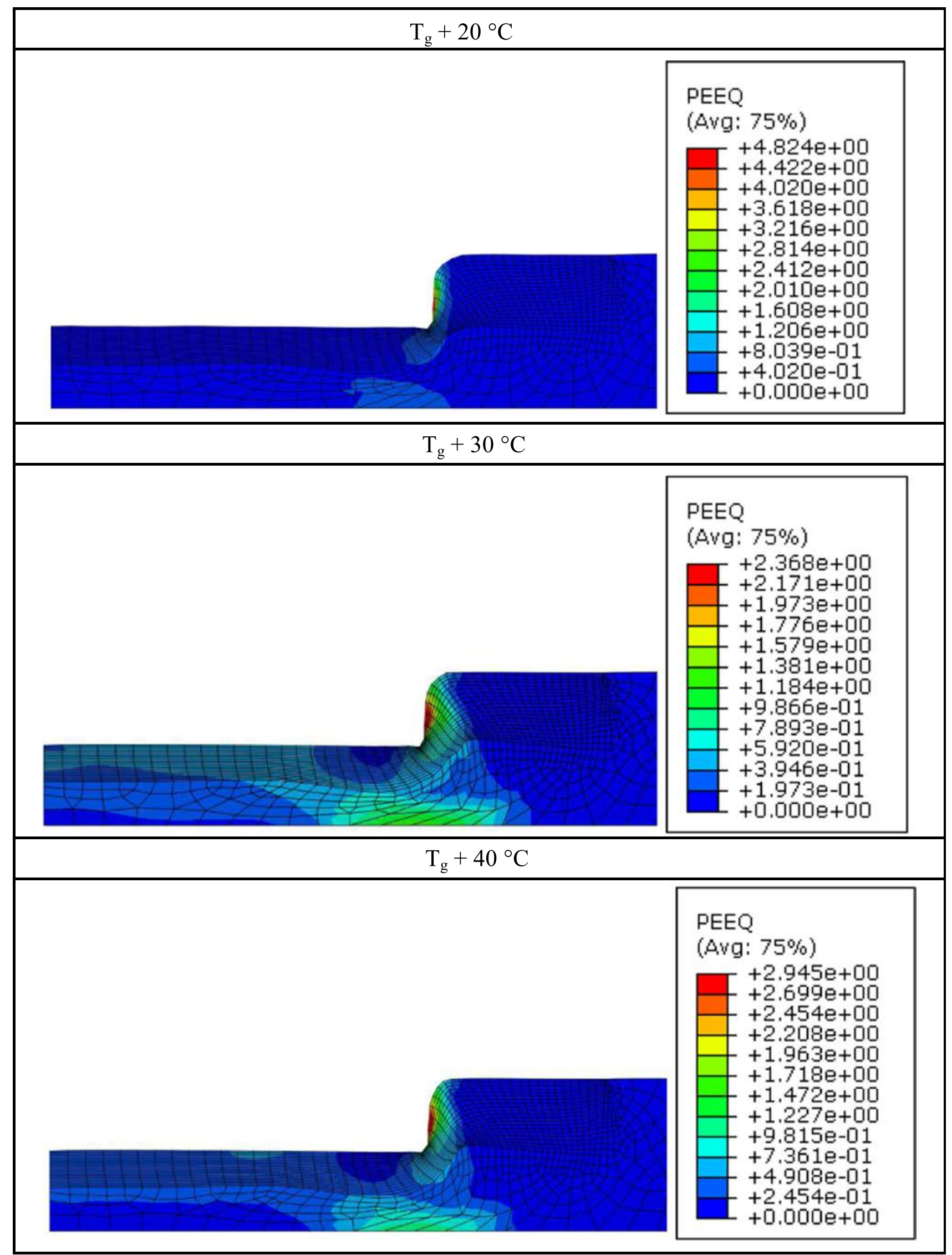

Fig. 9 Effective strain distribution of the polymer substrate in the axisymmetric model after the filling stage under different temperature conditions 


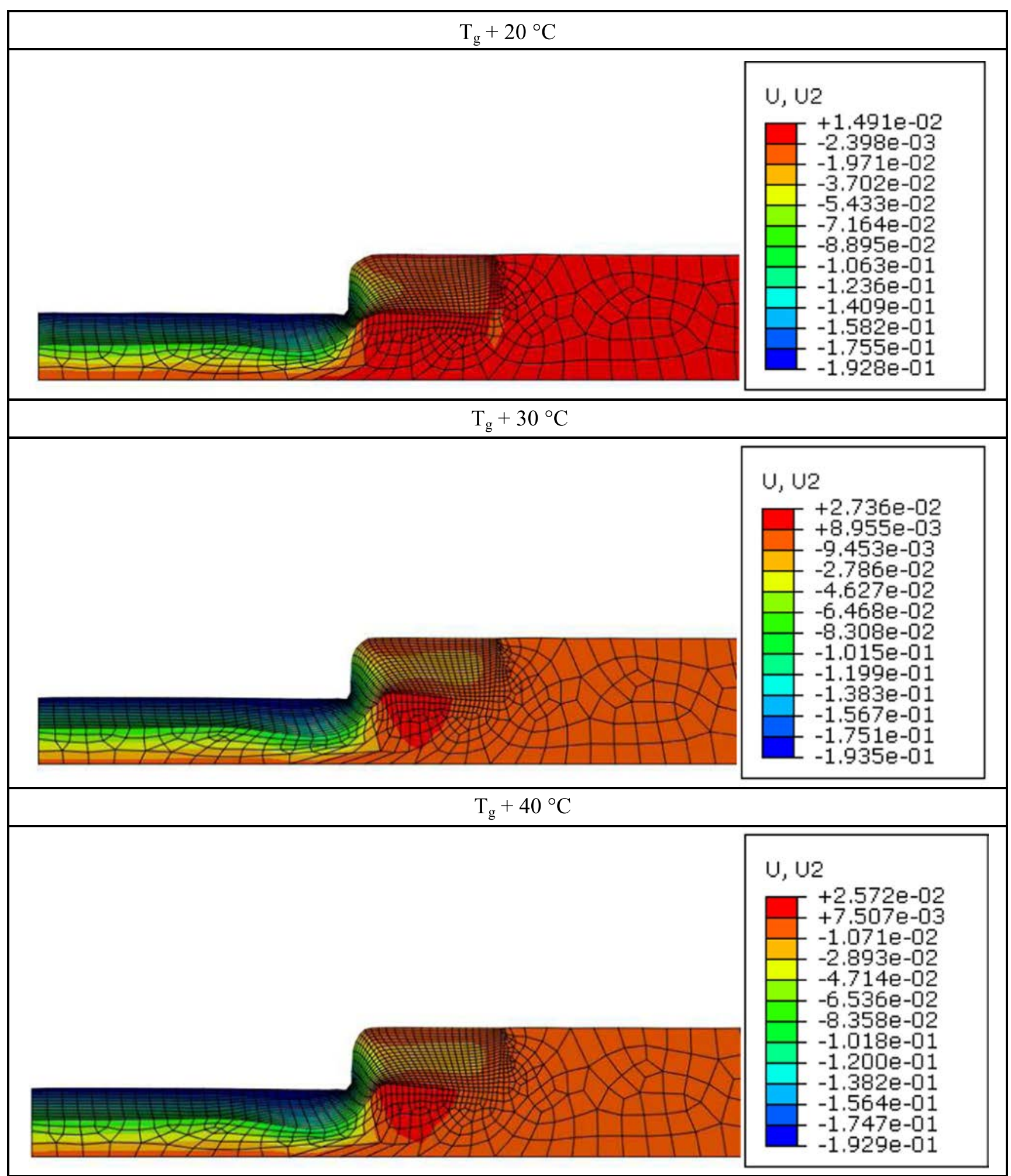

Fig. 10 Vertical displacement of the polymer in the axisymmetric model after the filling stage under different processing temperature conditions

small positive vertical displacement of the polymer substrate. The microfluidic cavities were almost filled by the polymer substrate under the three temperature conditions. However, there was always one small interspace in the polymer substrate that was not completely filled by the polymer.
To compare the filling efficiency at the microscale during the hot-embossing process under the three temperature conditions, the dimensions of the small interspace were investigated, as shown in Fig. 11a. As shown in Fig. 11a, d1 and h1 are defined as the length and height of the small interspace in the 
(a)

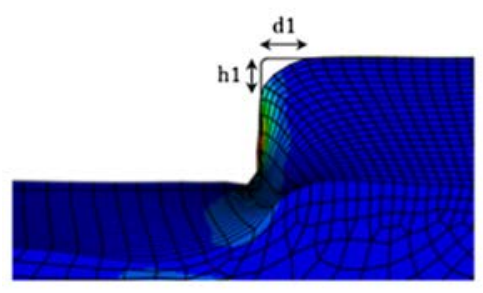

(b)

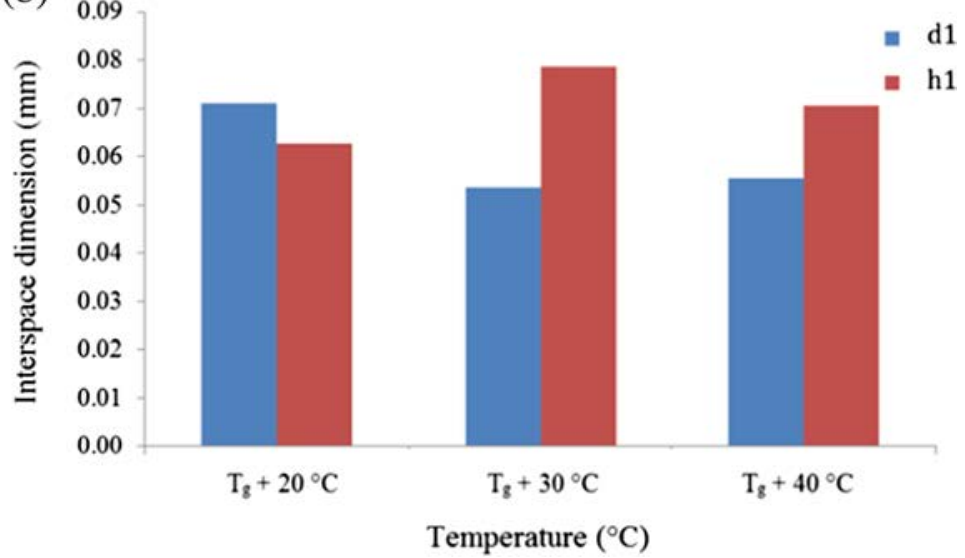

Fig. 11 a Small interspace in the polymer substrate in the axisymmetric model after the filling stage of the hot-embossing process. b Dimensions of the small interspace in the reservoir of the microfluidic device

axisymmetric model, respectively. The dimensions of the interspaces formed at three processing temperatures are shown in Fig. 11b. Efficiency of the filling polymer is achieved when the values of $\mathrm{d} 1$ and $\mathrm{h} 1$ are small. The best filling efficiency was obtained at $T_{g}+40^{\circ} \mathrm{C}$, because the values of $\mathrm{d} 1$ and $\mathrm{h} 1$ were smaller at $T_{g}+40^{\circ} \mathrm{C}$ than under the other conditions. As shown in Fig. 11b, the difference in the interspace dimensions is very small compared to the reservoir size. No significant difference in the dimensions of the interspace was observed for the three temperature conditions. The microcavity could not be completely filled in the filling step; however, almost $90 \%$ of the microcavity was filled with the polymer substrate. The polymer flow may continue to fill the microfluidic cavities in the subsequent step, and the filling efficiency may improve.

\subsection{Filling of the channel zone of the microfluidic device}

For the channel zone, a 2D plane strain model was created in the numerical software, with a channel width of $0.34 \mathrm{~mm}$ and height of $0.20 \mathrm{~mm}$. The length of the section was sufficiently long to observe the whole deformation of the channel zone. The friction between the substrate and the mould was not taken into account in this model. The PMMA was first heated to $T_{g}+20^{\circ} \mathrm{C}$; then it was heated to $T_{g}+30^{\circ} \mathrm{C}$, and finally to $T_{g}+40{ }^{\circ} \mathrm{C}$. The mould plate dropped by approximately $0.2 \mathrm{~mm}$ to compress the polymer substrate. The polymer substrate was compressed and filled the microcavities on both sides. In Fig. 12, the arrows indicate the direction of movement of the polymer substrate. The polymer at the bottom of the channel was compressed downwards and spilled over to fill the cavities on each side. The polymer at the top surface of the channel flowed towards the centre of the channel to fill the cavities.

As shown in Fig. 13, the von Mises stress of the polymer decreases with the increase in temperature from $T_{g}+20{ }^{\circ} \mathrm{C}$ to
$T_{g}+40{ }^{\circ} \mathrm{C}$. The stress distribution is symmetrical around the centreline of the channel. Less compression force is required to compress the polymer substrate at the higher temperature. The most important stress value in the polymer substrate appears at the bottom of the channel, which exhibits maximum deformation of the polymer substrate. The polymer at the bottom of the channel was pushed from the centre of the channel towards the edge to fill the cavities in the mould die. The polymer at the top surface of the channel moves towards the centre of the channel. Therefore, a small stress is observed in this area.

The effective strain distributions of the polymer substrate under processing temperature conditions of $T_{g}+20^{\circ} \mathrm{C}, T_{g}+$ $30^{\circ} \mathrm{C}$, and $T_{g}+40^{\circ} \mathrm{C}$ are presented in Fig. 14 . Similar observations could be obtained as with the axisymmetric model. For all of the temperature conditions, the highest effective strains occurred in the contour of the channels because the polymer flow has been pushed up to fill the microcavities in the mould die. The effective strain is symmetric around the centreline of the channel. There is a zone in the middle of the polymer substrate under the bottom of the channel where the effective strain is smaller than that in the contour because in this zone, the polymer flow is compressed by the mould die and simultaneously pushed by the polymer flow on the right and left sides. This zone is smaller at $T_{g}+20^{\circ} \mathrm{C}$ and becomes lager at $T_{g}+30{ }^{\circ} \mathrm{C}$ and $T_{g}+40{ }^{\circ} \mathrm{C}$, which indicates more plastic behaviour at a lower processing temperature. The highest effective strains occur under the temperature condition of $T_{g}+20^{\circ} \mathrm{C}$. This signifies that the polymer substrate exhibits more plastic behaviour at $T_{g}+20^{\circ} \mathrm{C}$, which is consistent with the investigation of the material characterisation.

In Fig. 15, the vertical displacement of the polymer substrate in the 2D plane strain model is shown for three temperature conditions. The heights of the embossed cavities in the polymer substrate are $0.1937 \mathrm{~mm}, 0.1941 \mathrm{~mm}$, and $0.1941 \mathrm{~mm}$ for $T_{g}+20^{\circ} \mathrm{C}, T_{g}+30^{\circ} \mathrm{C}$, and $T_{g}+40^{\circ} \mathrm{C}$, respectively. The polymer at the bottom of the channel was 


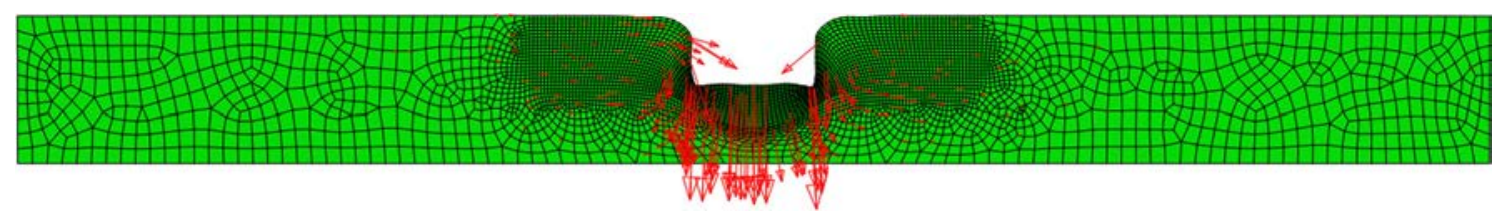

Fig. 12 Polymer flow direction in the 2D plane strain model of the filling step

compressed towards the edge to fill the cavities of the microfluidic device. The replicated component is symmetrical around the centreline of the channel. Similar to the situation in the axisymmetric model, the polymer at the top surface was raised and then compressed by the mould. As a result, there is a small positive vertical displacement of the replicated component. The microcavities at the edge of the channel were almost filled by the polymer substrate under the three temperature conditions. However, there is always a small interspace at each side of the channel in the polymer substrate that is not completely filled with the polymer.

To compare the different filling efficiencies of the microchannels under the three processing temperature conditions, the dimensions of the small interspace were investigated, as shown in Fig. 16a. As shown in Fig. 16a, $d 2$ and $h 2$ are defined as the length and height of the small interspace in the 2D plane strain model, respectively. The dimensions of the interspace formed under three processing temperatures are shown in Fig. 16b. Good filling efficiency is achieved when the values of $\mathrm{d} 2$ and $\mathrm{h} 2$ are small. The same conclusion could be reached as for the microreservoir: the best filling efficiency of the microchannels was obtained at $T_{g}+40{ }^{\circ} \mathrm{C}$, corresponding to the maximal forming process temperature, because the values of $d 2$ and $h 2$ are smaller at $T_{g}+40^{\circ} \mathrm{C}$ than at the other temperature conditions. Based on the dimensions of the small interspace, the value of $d 2$ is much more important than that of $h 2$. This indicates that the microcavities are filled more effectively by the PMMA flow in the vertical direction than that in the horizontal direction. The difference in the interspace dimensions is very small compared to the channel size, as shown in Fig. 16. No significant difference in the dimensions of the interspace was observed in the three temperature conditions. The microcavities could not be completely filled in this filling step; nevertheless, almost $90 \%$ of the microcavities were filled with the polymer substrate. The polymer flow may continue to fill the microfluidic cavities in the next step, and the filling efficiency may be improved.

\section{Comparison of simulation and experimental results}

The filling stage of the micro hot-embossing process was modelled by considering the elastoplastic behaviour of the PMMA polymers. Two specific parts of the microfluidic device, the reservoir and the channel, were investigated in the numerical simulation example. The numerical simulation results need to be compared to the experimental results to evaluate the accuracy of the model for the micro hot-embossing process.

Microfluidic devices with the same geometric patterns were replicated successfully through micro hot-embossing in our previous study [5]. The PMMA substrate was embossed using the mould die by $0.20 \mathrm{~mm}$ at $T_{g}+40^{\circ} \mathrm{C}$ through the hotembossing process. The microfluidic devices fabricated from the PMMA substrate were optically transparent, and thus, it was difficult to measure their dimensions directly with optical equipment. Therefore, room-temperature vulcanising (RTV) silicone rubber was used to replicate the negative micropattern of the microfluidic devices. As shown in Fig. 17, the height of the replicated reservoir and channel is approximately $210 \mu \mathrm{m}$ in these experiments. As determined in the numerical simulation in the previous study, the height of the reservoir is $192.9 \mu \mathrm{m}$, whilst that of the channel is $194.1 \mu \mathrm{m}$. The difference between the numerical and experimental results is approximately $20 \mu \mathrm{m}$, which is likely due to deviation in the manufacturing of the mould die insert for the microfluidic device and discrepancies during the measurement of the dimensions of the microcavities. The numerical results show good agreement for the prediction of the polymer substrate deformation in the replication of a microfluidic device using the hot-embossing process.

\section{Conclusions}

This study focuses on the physical modelling of an amorphous thermoplastic polymer and a numerical simulation of the micro hot-embossing process. The main contribution is the characterisation of the mechanical properties of the amorphous thermoplastic polymer in a temperature range slightly higher than its glass transition temperature. In this temperature range, the polymers exhibit elastic, viscoelastic, and viscoplastic behaviour together. The polymer viscoplastic properties were characterised in a temperature range slightly above its glass transition temperature. Numerical simulation of the filling stage of the micro hot-embossing process was performed successfully. The effects of temperature on the filling ratio of the microcavities (channel and reservoir) were analysed to optimise the hot-embossing process with the PMMA amorphous thermoplastic polymer. The results of the simulation were in 


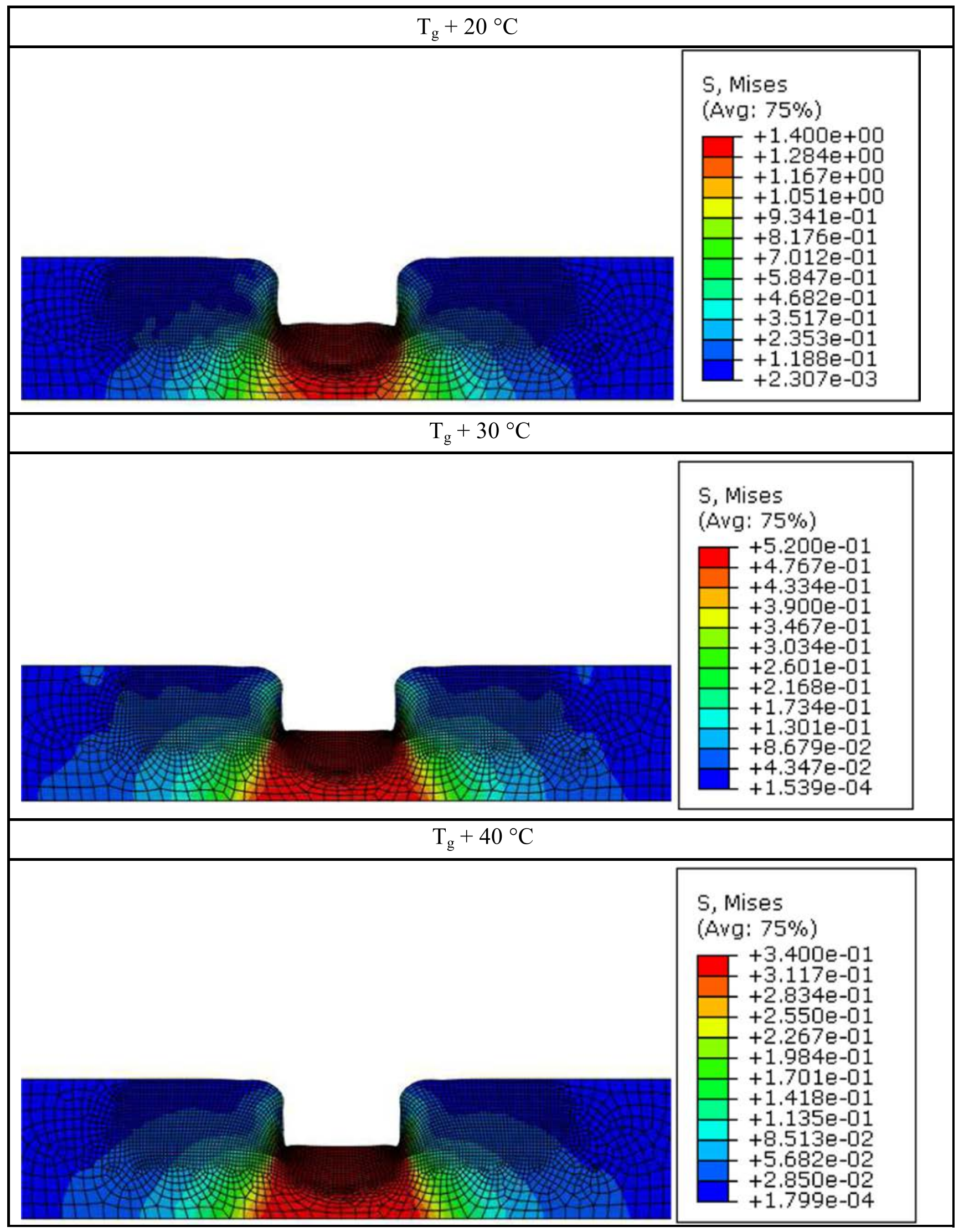

Fig. 13 Von Mises stress of the polymer substrate in the 2D plane strain model after the filling stage under different temperature conditions 


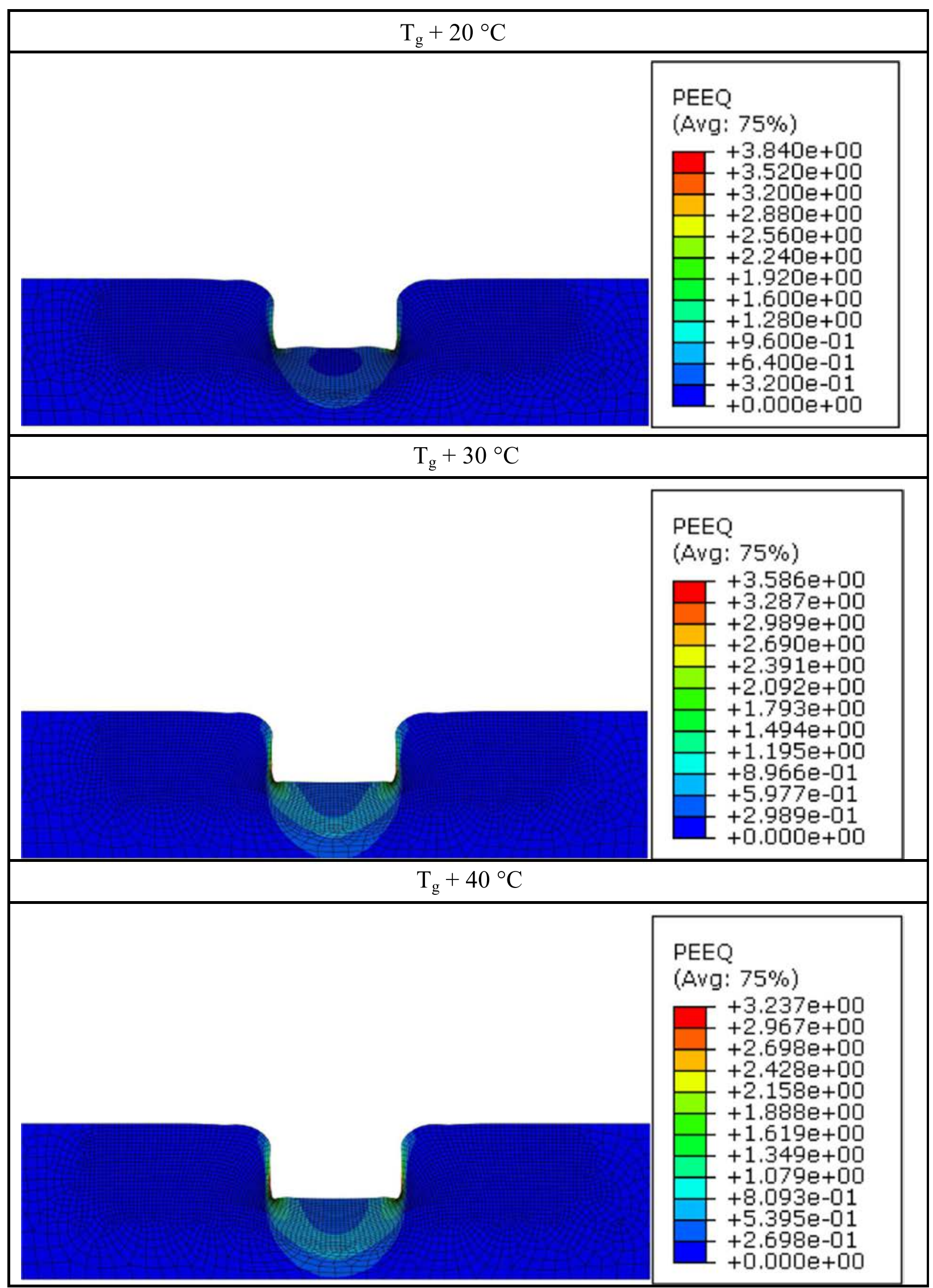

Fig. 14 Effective strain distributions of the polymer substrate in the 2D plane strain model after the filling stage under different temperature conditions 


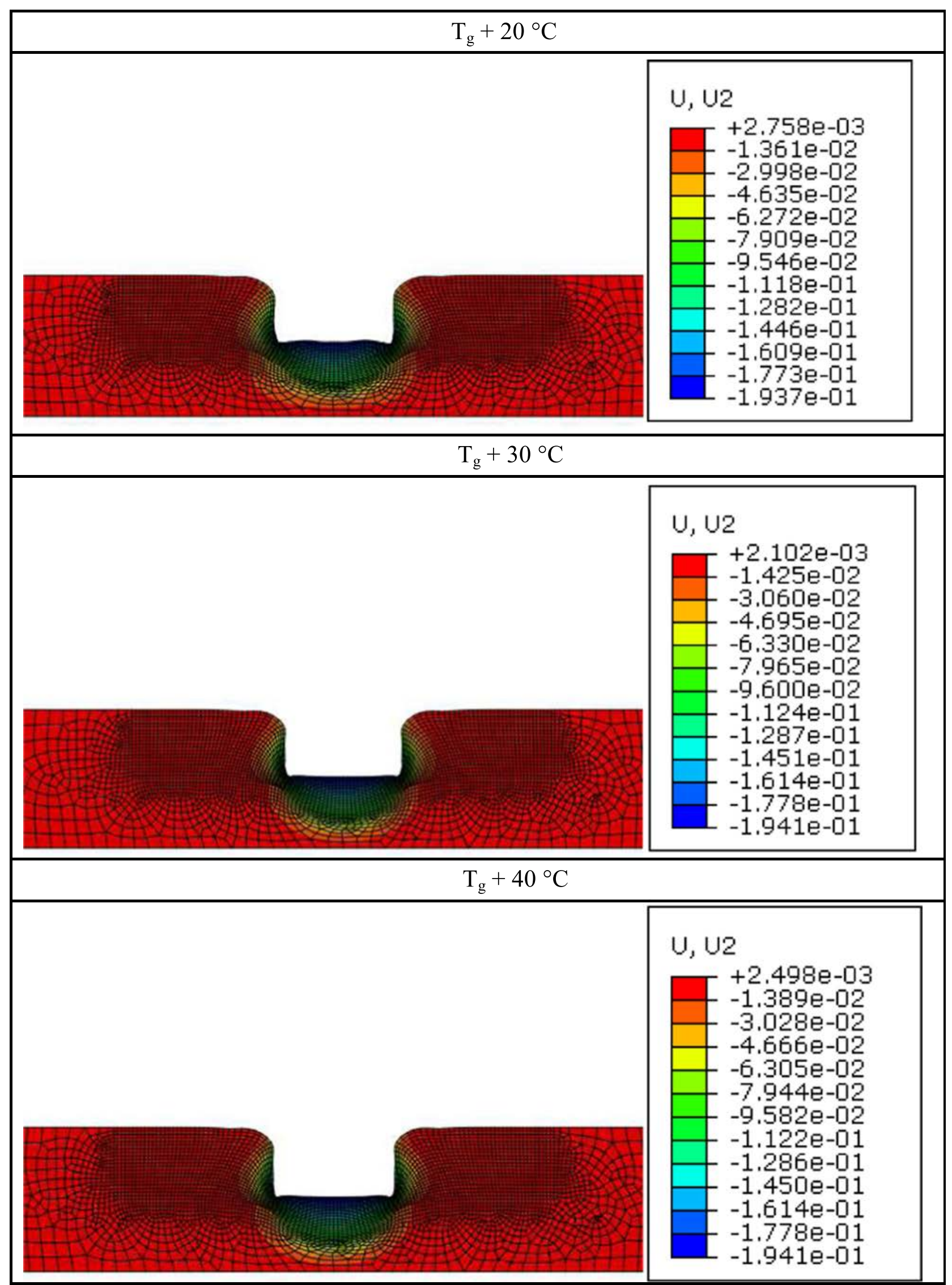

Fig. 15 Vertical displacement of the polymer substrate in the 2D plane strain model after the filling stage under different temperature conditions 
(a)

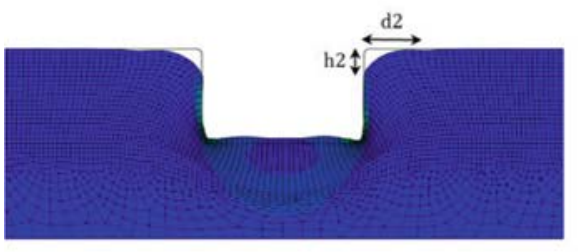

(b)

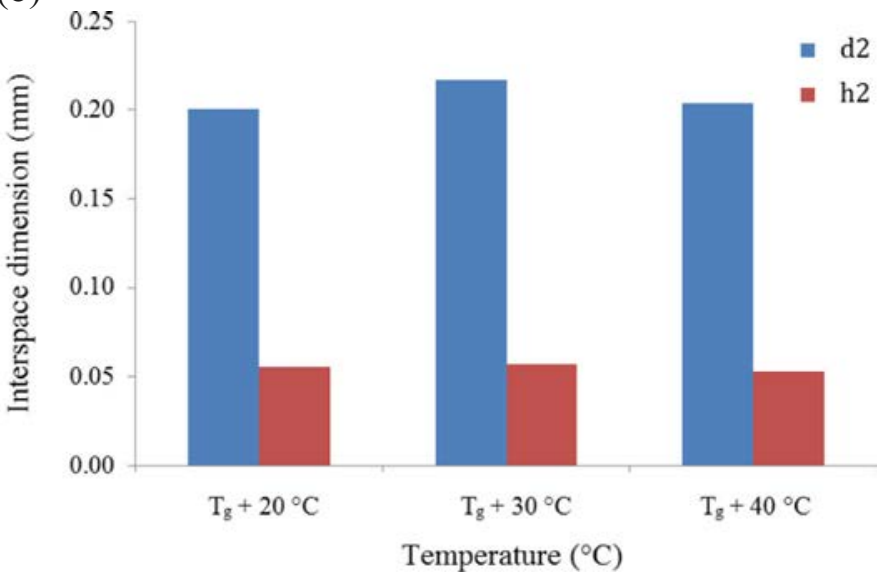

Fig. 16 a Small interspace in the polymer substrate in the 2D plane strain model after the filling step of the hot-embossing process. $\mathbf{b}$ Dimensions of the small interspace in the channels of the microfluidic device

good agreement with the experimental results in terms of replication on a microscale.

Uniaxial compression tests with PMMA specimens were carried out under different hot-embossing temperature conditions. The elastic modulus of the amorphous polymer was obtained at temperature conditions of $T_{g}+20{ }^{\circ} \mathrm{C}, T_{g}+$ $30{ }^{\circ} \mathrm{C}$, and $T_{g}+40{ }^{\circ} \mathrm{C}$, which correspond to the processing temperature range for the micro hot-embossing process. The elastic-plastic behaviour of PMMA was identified with the true stress-strain curves obtained from large-deformation compression tests. The viscoelastic properties of PMMA were characterised using the true stress versus time and true strain versus time curves obtained from the compression relaxation tests. The relaxation moduli of the polymer at six strain levels were obtained with respect to time. A good agreement between the identification and experimental data was obtained, suggesting the potential for the application of numerical simulations of the hot-embossing processes.

The numerical simulations realised with the proposed viscoplastic model implemented in finite element software specifically investigated the filling stage at the microscale in two different zones (channel and reservoir). The filling step during the hot-embossing process was analysed to investigate the filling efficiency of the amorphous polymer flow into the mould die cavities. Two numerical models were created in the software: an axisymmetric model for simulation of the reservoir zone and a plane strain model for simulation of the channel zone. The elastic-plastic behaviour of the amorphous polymer was taken into account in the numerical simulation of the filling step of the micro hot-embossing process. Most of the microcavities were filled by the polymer flow, with the exception of a small interspace near the edge of the mould insert. The dimensions of this small interspace were measured to compare the filling efficiency at different embossing temperatures.

The investigation of microfluidic devices fabricated by micro hot-embossing using the amorphous polymer was realised in this study through a case study comparing the experimental and numerical results with different processing and material parameters. Specific related studies in the processing temperature range of $T_{g}+20{ }^{\circ} \mathrm{C}$ to $T_{g}+40{ }^{\circ} \mathrm{C}$ with different filling efficiencies for different material parameters were discussed and compared in this paper. As shown in the experimental investigation, the height of the PMMA replicated reservoir and channel was about $210 \mu \mathrm{m}$. In the numerical simulation,
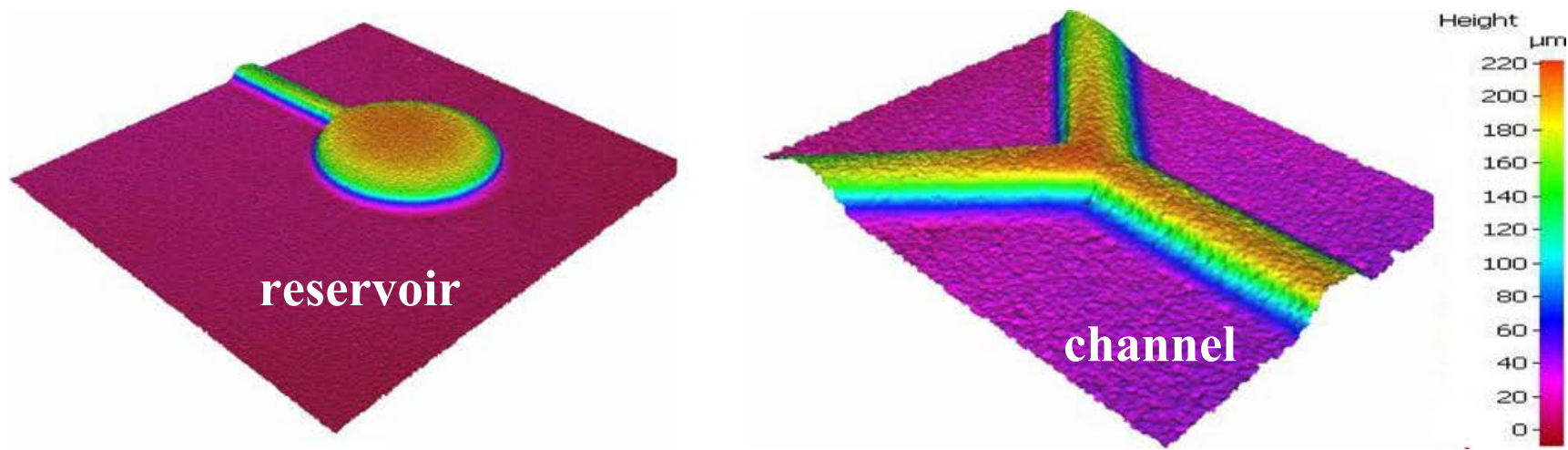

Fig. 17 The 3D images of the reservoir and channel zones of the RTV silicone microfluidic obtained using the micro hot-embossing process [5] 
the height of the reservoir was $192.9 \mu \mathrm{m}$ and that of the channel was $194.1 \mu \mathrm{m}$. The difference between the simulation results and the experimental results was approximately $20 \mu \mathrm{m}$, which was probably due to deviations in the manufacturing of the mould die insert for the microfluidic device and/or the discrepancies during the microscale measurement of the dimensions of the microcavities. The simulation results show suitable agreement for the microscale prediction of polymer substrate deformation during replication of a complex microfluidic using the hot-embossing process, validating the implemented model in the finite element software and confirming the efficacy of the proposed approach with different comparisons in 2D and 3D cases. The results of this study will be helpful for improving the microreplication quality in the micro hot-embossing process.

\section{References}

1. Abaqus User's Manual (2016) Dassault Systèmes, Providence, RI

2. Andersen TE, Andersen AJ, Petersen RS, Nielsen LH, Keller SS (2018) Drug loaded biodegradable polymer microneedles fabricated by hot embossing. Microelectron Eng 195:57-61

3. Bardenhagen SG, Stout MG, Gray GT (1997) Three-dimensional, finite deformation, viscoplastic constitutive models for polymeric materials. Mech Mater 25:235-253

4. Becker H, Heim U (2000) Hot embossing as a method for the fabrication of polymer high aspect ratio structures. Sensor Actuat A-Phys 83:130-135

5. Cheng G, Sahli M, Gelin J-C, Barriere T (2016) Physical modelling, numerical simulation and experimental investigation of microfluidic devices with amorphous thermoplastic polymers using a hot embossing process. J Mater Process Technol 229:36-53

6. Dreistadt C, Bonnet A-S, Chevrier P, Lipinski P (2009) Experimental study of the polycarbonate behaviour during complex loadings and comparison with the Boyce, Parks and Argon model predictions. Mater Design 30:3126-3140

7. Drozdov AD (2001) A model for the viscoelastic and viscoplastic responses of glassy polymers. Int J Solids Struct 38:8285-8304

8. Esmaeilpour R, Kim H, Park T, Pourboghrat F, Mohammed B (2017) Comparison of 3D yield functions for finite element simulation of single point incremental forming (SPIF) of aluminum 7075. Int J Mech Sci 133:544-554

9. Esmaeilpour R, Kim H, Park T, Pourboghrat F, Xu Z, Mohammed B, Abu-Farha F (2018) Calibration of Barlat Yld2004-18P yield function using CPFEM and 3D RVE for the simulation of single point incremental forming (SPIF) of 7075-O aluminum sheet. Int $\mathrm{J}$ Mech Sci 145:24-41

10. Federico CE, Bouvard JL, Combeaud C, Billon N (2018) Large strain/time dependent mechanical behaviour of PMMAs of different chain architectures. Application of time-temperature superposition principle. Polymer 139:177-187

11. Frank GJ, Brockman RA (2001) A viscoelastic-viscoplastic constitutive model for glassy polymers. Int J Solids Struct 38:5149-5164

12. Gudimetla MR, Doghri I (2017) A finite strain thermodynamicallybased constitutive framework coupling viscoelasticity and viscoplasticity with application to glassy polymers. Int J Plast 98: 197-216
13. Holmes DW, Loughran JG (2008) Theoretical aspects of the testing of elasto-viscoelastic-viscoplastic materials. Polym Test 27:189-203

14. Holopainen S, Barriere T (2018) Modeling of mechanical behavior of amorphous solids undergoing fatigue loadings, with application to polymers. Comput Struct 199:57-73

15. Hu W, Guo H, Chen Y, Xie R, Jing H, He P (2016) Experimental investigation and modeling of the rate-dependent deformation behavior of PMMA at different temperatures. Eur Polym J 85:313-323

16. Kim SH, Chung JW, Kang TJ, Kwak S-Y, Suzuki T (2007) Determination of the glass transition temperature of polymer/ layered silicate nanocomposites from positron annihilation lifetime measurements. Polymer 48:4271-4277

17. Kim J-S, Muliana AH (2010) A combined viscoelastic-viscoplastic behavior of particle reinforced composites. Int J Solids Struct 47: 580-594

18. Kurita T, Ogura I, Ashida K (2018) Proposal of laser assisted hot embossing technology for glass. J Mater Process Technol 254:248 253

19. Lee TY, Han K, Barrett DO, Park S, Soper SA, Murphy MC (2018) Accurate, predictable, repeatable micro-assembly technology for polymer, microfluidic modules, Sens. Actuators, B 254:1249-1258

20. Liang C, Meng F, Li J, Liu C (2018) Using $\mathrm{CO}_{2}$-laser bugle for ultrasonic bonding of thermoplastic microfluidic devices. J Mater Process Technol 252:25-33

21. Mareau C, Favier V, Berveiller M (2009) Micromechanical modeling coupling time-independent and time-dependent behaviors for heterogeneous materials. Int J Solids Struct 46:223-237

22. Mathur A, Roy SS, Tweedie M, Mukhopadhyay S, Mitra SK, McLaughlin JA (2009) Characterisation of PMMA microfluidic channels and devices fabricated by hot embossing and sealed by direct bonding. Curr Appl Phys 9:1199-1202

23. Oliveira J, Correia V, Castro H, Martins P, Lanceros-Mendez S (2018) Polymer-based smart materials by printing technologies: improving application and integration. Addit Manuf 21:269-283

24. Srivastava V, Chester SA, Ames NM, Anand L (2010) A thermomechanically-coupled large-deformation theory for amorphous polymers in a temperature range which spans their glass transition. Int J Plast 26:1138-1182

25. Voyiadjis GZ, Shojaei A, Li GQ (2012) A generalized coupled viscoplastic-viscodamage-viscohealing theory for glassy polymers. Int J Plast 28:21-45

26. Wang J, Yi P, Deng Y, Peng L, Lai X, Ni J (2017) Recovery behavior of thermoplastic polymers in micro hot embossing process. $\mathrm{J}$ Mater Process Technol 243:205-216

27. Worgull M, Heckele M (2004) New aspects of simulation in hot embossing. Microsyst Technol 10:432-437

28. Worgull M (2009) Hot Embossing Tools. In: Hot embossing: theory and Technology of Microreplication. Elsevier Inc, Burlington

29. Xiao R, Sun HG, Chen W (2017) A finite deformation fractional viscoplastic model for the glass transition behavior of amorphous polymers. Int J Nonlinear Mech 93:7-14

30. Yu C, Kang G, Chen K, Lu F (2017) A thermo-mechanically coupled nonlinear viscoelastic-viscoplastic cyclic constitutive model for polymeric materials. Mech Mater 105:1-15

31. Zairi F, Nait-Abdelaziz M, Woznica K, Gloaguen J-M (2005) Constitutive equations for the viscoplastic-damage behaviour of a rubber-modified polymer. Eur J Mech A-Solid 24:169-182

32. Zhang N, Srivastava AP, Browne DJ, Gilchrist MD (2016) Performance of nickel and bulk metallic glass as tool inserts for the microinjection molding of polymeric microfluidic devices. $\mathrm{J}$ Mater Process Technol 231:288-300 